\title{
Current status of immunoglobulin $M$ seroprevalence in women with adverse reproductive outcomes in current pregnancy: experience in a teaching institution
}

\author{
Sana Tiwari ${ }^{1}$, Balvinder Singh Arora ${ }^{2}$, Poornima Sen ${ }^{2}$, Rupali Dewan ${ }^{1}$ \\ ${ }^{1}$ Department of Obstetrics and Gynaecology, ${ }^{2}$ Department of Microbiology, V.M.M.C. and Safdarjang Hospital, New
} Delhi, India

Received: 05 August 2016

Accepted: 06 September 2016

*Correspondence:

Dr. Balvinder S. Arora,

E-mail: dr_arorabalvinder007@yahoo.com

Copyright: ( $\odot$ the author(s), publisher and licensee Medip Academy. This is an open-access article distributed under the terms of the Creative Commons Attribution Non-Commercial License, which permits unrestricted non-commercial use, distribution, and reproduction in any medium, provided the original work is properly cited.

\section{ABSTRACT}

Background: During pregnancy, the immune system is suppressed, making the individual susceptible to infections. One of the most common causes of perinatal mortality in developing countries is TORCH infections. Screening for TORCH agents during pregnancy identifies high risk mothers thereby providing the clinician with opportunity to intervene.

Methods: A total of two hundred women with adverse pregnancy events in current pregnancy formed the study group while 150 women with normal pregnancy outcome formed control group. Presence of IgM antibodies against TORCH agents were detected by ELISA and results expressed qualitatively as positive or negative.

Results: Our study revealed $45.56 \%$ women in current pregnancy were positive for IgM serology while in controls it was only $14.67 \%$ ( $\mathrm{p}$ value $<0.0001$ ). The percentage frequency of TORCH agents in terms of IgM seropositivity for toxoplasma was as $14.63 \%, 15.86 \%$ for rubella, $23.17 \%$ for CMV, $46.34 \%$ for HSV.

Conclusions: It may not be possible to screen all patients with adverse reproductive outcome for TORCH but all women with adverse reproductive outcome in current pregnancy should be subjected to TORCH testing, especially to safeguard future pregnancies. The affected females should be counseled regarding continuation of pregnancy but remain under observation and treatment. Positive serology findings as supportive evidence to clinical diagnosis, if kept in consideration, may help manage future pregnancies more effectively.

Keywords: TORCH, IgM seroprevalence, Pregnancy, ELISA

\section{INTRODUCTION}

TORCH infections are unique in their pathogenesis and have potentially devastating clinical manifestations. In most cases maternal infection is mild but the impact on the developing foetus is enormous with vast array of symptoms. TORCH infections during pregnancy are a potential cause for congenital infections, abortions, intrauterine growth restriction (IUGR), still births and intrauterine deaths (IUD). Diagnosis of acute TORCH infection in pregnant women is usually established by demonstration of sero-conversion in paired sera or by demonstration of specific IgM antibodies. Since variations have been reported about seroprevalence in Indian studies therefore the present study was undertaken to estimate the seroprevalence of TORCH infections in current pregnancy, especially in present times, employing more sensitive and specific ELISA test. ${ }^{1}$

\section{METHODS}

A total of 200 women formed the study group which were negative for any previous serological evidence for any of the TORCH agent either IgM/IgG positive. Known cases of chronic medical illness which can affect pregnancy viz. diabetes, hypertension, chronic renal 
disease were excluded from the study. Cases with other obstetrical causes likely to affect the current pregnancy for example Rh incompatibility, eclampsia, preeclampsia, APH, uterine anomaly defects, or any other related illness were also excluded from the study. Pregnant females with neural tube defects including anencephaly in current pregnancy were also not included in the study because neural tube defects are not due to TORCH. A total of 150 women with normal pregnancy outcome formed our control group. Detailed obstetrical history, physical and obstetrical examinations were undertaken in all the cases. Routine antenatal investigations and ultra-sonograms were done and recorded. Out of the said 200 cases, a total of 197 serum samples could be collected. Of these 17 samples were found not suitable for serology due to these having been haemolysed or apparently contaminated thereby making the sample size 180 . In all these 180 sera and 150 control sera, presence of $\operatorname{IgM}$ antibodies against TORCH agents were detected by ELISA and results were recorded and expressed qualitatively as positive or negative.

\section{RESULTS}

Results revealed that of the total 180 cases, $45.56 \%$ were TORCH IgM seropositive while among controls only $14.67 \%$ were seropositive ( $\mathrm{p}$ value $<0.0001$ ) (Table 1 ).

Table 1:IgM antibodies serology status of TORCH agents in cases and controls.

\begin{tabular}{|llll|}
\hline TORCH IgM serology & & \\
\hline \multirow{2}{*}{$\begin{array}{l}\text { Total } \\
\text { sera }\end{array}$} & Cases 180 & Positive & Negative \\
\cline { 2 - 4 } 330 & Controls 150 & $22(14.67 \%)$ & $128(85.33 \%)$ \\
\hline \multirow{2}{*}{ p-value } & & $<0.0001$ & \\
\hline
\end{tabular}

Among 82 seropositive cases in study group-14.63\% were positive for toxoplasma, $15.86 \%$ for rubella, $23.17 \%$ for CMV, and $46.34 \%$ for HSV TORCH agents respectively (Table 2).

Table 2: TORCH IgM antibodies percent distribution in 82 seropositive cases among study group and 22 seropositive cases in control group.

\begin{tabular}{|llllll|}
\hline TORCH agent & Seropositivity & (cases; $\mathbf{n = 8 2}$ ) & \multicolumn{2}{l|}{ Seropositivity (controls; $\mathbf{n = 2 2}$ ) } \\
\hline & Number & $\mathbf{\%}$ & Number & \% & p value \\
\hline Toxoplasma & 12 & 14.63 & 3 & 13.64 & 0.904 \\
\hline Rubella & 13 & 15.86 & 5 & 22.72 & 0.447 \\
\hline CMV & 19 & 23.17 & 3 & 13.64 & 0.332 \\
\hline HSV & 38 & 46.34 & 11 & 50.00 & 0.756 \\
\hline Total & $\mathbf{8 2}$ & $\mathbf{1 0 0}$ & $\mathbf{2 2}$ & $\mathbf{1 0 0}$ & \\
\hline
\end{tabular}

Table 3: TORCH IgM seropositivity percent distribution with respect to different adverse reproductive outcomes in study group.

\begin{tabular}{|lllll|}
\hline \multirow{2}{*}{$\begin{array}{l}\text { Adverse reproductive } \\
\text { outcome }\end{array}$} & TORCH positive $(\mathbf{n = 8 2})$ & TORCH negative $(\mathbf{n = 9 8})$ & $\%$ \\
\hline Abortions & Number & $\%$ & Number & 37.75 \\
\hline IUGR & 26 & 31.70 & 37 & 28.57 \\
\hline IUD & 28 & 34.14 & 28 & 20.40 \\
\hline GCA & 19 & 23.17 & 20 & 13.26 \\
\hline & 09 & 10.97 & 13 & 98 \\
\hline
\end{tabular}

For adverse reproductive outcomes TORCH seropositivity was found highest in IUGR (34.14\%) followed by abortions (31.70\%), IUD (23.17\%) and GCA (10.97\%) (Table 3).

\section{DISCUSSION}

In our study based on ELISA testing, evidence of TORCH infections were observed in $45.5 \%$ of cases and only in $14.6 \%$ in controls (Table 1 ). In a study by D Turbadkar et al, TORCH infections were noted in 17 out of 40 patients i.e. $42.5 \%$ of cases in association with IgM antibodies. Similar observation of mixed infection is also reported by Mookherjee $\mathrm{N}$ et al in a study entitled microbiology evaluation of women with bad obstetric history. ${ }^{2}$ The results of our study revealed that difference in percent incidence of $\operatorname{IgM}$ antibodies positivity status in cases and controls is statistically significant clearly reflecting that assessment of $\operatorname{IgM}$ serology status in women with adverse reproductive outcome in current pregnancy is important in Indian context. 


\section{Toxoplasma}

In present study the seroprevalence of toxoplasma IgM among pregnant women with adverse reproductive outcomes is observed at $14.63 \%$ while in controls it is $13.64 \%$. Janak $\mathrm{K}$ et al reported overall $\mathrm{IgM}$ antibody positivity of $8.3 \%$ in 60 cases of $\mathrm{BOH}^{3}$ A study by Kaur $\mathrm{R}$, et al has demonstrated $\operatorname{IgM}$ seropositivity of toxoplasmosis as $11.6 \%$. $^{4}$ Sadik MS, et al and Turbadkar $\mathrm{D}$, et al have also reported an incidence of $18 \%$ and $10.5 \%$ respectively. ${ }^{5,1}$ The Indian studies have overall, shown varied results ranging from $11-55 \% .^{6}$ Our study shows lack of decline in sero-prevalence of toxoplasma in Indian population especially from north part of India as is also present study group. Present study reinforces that antenatal screening of pregnant mothers for toxoplasma IgM seropositivity is very useful as it reflects primary infection or reactivation phenomenon with pathogen activity in progress. Statistical analysis, although shows that the differences between cases and controls are not significant but the incidence based on seroprevalence suggest that toxoplasma screening in cases with high index of clinical suspicion is important not only in current pregnancy but also for the benefit of future newborn in future pregnancies. Since, the impact of toxoplasma appears later in life of foetus, its evidence, if known earlier would help for follow up on periodic basis and also help clinician prepare better for management of the complications later in life.

\section{Rubella}

In the present study, IgM seropositivity of adverse reproductive outcomes for rubella is observed at $15.86 \%$ while it is $22.72 \%$ in controls (p value 0.447 ). A study by Padmavaty et al reported it as $3.3 \%$. Another study by Surpam RB, et al and Yasodhara et al have reported IgM antibody positivity of 4.66 and $6.5 \%$ respectively in cases of adverse reproductive outcomes. ${ }^{8-10}$ In present study, results are statistically insignificant but the incidence is relatively high. Obstetricians reserve the opinion because for case management $\operatorname{IgM}$ seroprevalence is more important and reliable and the ELISA test utilized for the seroprevalence determination is more than $99.4 \%$ sensitive and $99.2 \%$ specific. It is important to mention that rubella is highly infectious virus and has devastating effects on the fetus. Although recent studies have shown that majority of Indian population is relatively immune to rubella but present study shows relatively high seroprevalence $(>15 \%)$ suggesting that probably pockets in population domains likely to contract acute rubella infection do exist, especially where immunization coverage is either unplanned or may be nonexistent.

\section{CMV}

The present study has revealed seropositivity rate of $23.17 \%$ in cases with adverse reproductive outcomes and $13.64 \%$ in controls. Seroprevalence assessment by ELISA test of $20 \%$ has been reported in Delhi. ${ }^{4}$ Another
Indian study reported CMV $\operatorname{IgM}$ positivity at $12.9 \% .^{11}$ Statistically analyzed, it is a not significant finding with a p-value of 0.332 . Primary CMV infection in pregnancy has a higher incidence of symptomatic congenital infection and foetal loss. ${ }^{8}$ The infection being asymptomatic in adults is clinically difficult to diagnose. Demonstration of $\operatorname{IgM}$ antibodies is indicative of primary infection. Detection of $\operatorname{IgM}$ seropositivity status in mother by reasonably sensitive and highly specific ELISA test is very useful and prepares the clinician to handle the newborn more effectively. Pediatricians, highly specialized in neonatology, can be alerted to render some lasting benefits by instituting judicious management protocols within the international guidelines during current pregnancies to render lasting benefits to the newborn and also for future pregnancies.

\section{HSV}

The seropositivity rate for HSV IgM among women with adverse reproductive outcomes, in our study, is observed as $46.34 \%$ in cases and only $50.00 \%$ in controls (p-value 0.756). In a study done in Varanasi, $33.5 \%$ of HSV-2 cases were reported by Sen MR, et al. Kaur R, et al reported the seropositivity of $48-68 \%$ in New Delhi. ${ }^{13,4}$ Primary infection with HSV acquired by women during pregnancy accounts for half of the morbidity and mortality from HSV among neonates while the other half results from reactivation of an old infection. ${ }^{12}$ The recurrence rate of genital herpes appears to be higher in pregnant women than in non-pregnant women. The chance of recurrence increases as patient reaches term. Nearly $25 \%$ of women with a history of genital herpes tend to have precipitous event at some point of time during last month of pregnancy and between 10-15\% have adverse outcomes or outbreak at the time of delivery. Risk of neonatal infection is as low as $1 \%$ if mother acquires infection in first trimester and it is due to formation of protective antibodies whereas the risk is highest almost to $30-50 \%$ if mother gets infection in last trimester. ${ }^{14}$ Testing for TORCH by ELISA test in current pregnancy, especially when there is evidence of impeding adverse reproductive outcome (as suggested by radiological evidence such as USG, physical examination) or event of adverse reproductive outcome having occurred in current pregnancy, would help clinician manage the patient better instituting appropriate treatment, including counseling, in future pregnancies for judicious family planning.

Funding: No funding sources

Conflict of interest: None declared

Ethical approval: The study was approved by the Institutional Ethics Committee

\section{REFERENCES}

1. Turbadkar D, Mathur M, Rele M. Seroprevalence of TORCH infections in bad obstetric history. Indian J Med Micro. 2003;21:108-10. 
2. Mookherjee N, Gogate A, Shah PK. Microbiology evaluation of women with bad obstetric history. Indian J Med Res. 1995;102:103-7.

3. Janak K, Richa M, Abhiruchi P, Yashodhra P. Adverse reproductive outcome induced by parvovirus B19 and TORCH infections in women with high risk pregnancy. J Infect Dev Ctries. 2011;5(12):868-73.

4. Kaur R, Gupta N, Nair D, Kakkar M, Mathur MD. Screening for torch infections in pregnant women: a report from Delhi. Southeast Asian J Tropical Medicine Public Health. 1999;30:284-6.

5. Sadik MS, Fatima F, Jamil K, Patil C. Study of TORCH profile in patients with bad obstetric history. J Bio Med. 2012;4(2):95-101.

6. Srirupa P, Nibedita D, Pal D. Seroprevalence and risk factors of toxoplasma gondii in pregnant women in Kolkata. India J Recent Advances Applied Sci. 2011;26:27-33.

7. Devi R, Sreenivas N, Rajangam S. Bad Obstetrics History and Infectious Causes. Int J Hum Gene. 2002;2(4):269-71.

8. Padmavathy M, Mangala G, Malini J, Umapathy BL, Navaneeth BV, Bhatia M, Harle S. Seroprevalence of TORCH infections and adverse reproductive outcome in current pregnancy with bad obstetric history. J Clin Biomed Sci. 2013;3(2):63-71.

9. Surpam RB, Kamlakar UP, Khadse RK, Qazi MS, Jalgaonkar SV. Sero-prevalence study for TORCH infections in women with bad obstetric history. J Obst Gynae India. 2006;56:41-3.

10. Yashodhara P. Prevlance of TORCH infections in Indian pregnant women. Indian $\mathrm{J}$ Med Microb. 2002;20:57-8.

11. Kapil A, Broor S. Primary cytomegalovirus infection in pregnant and non-pregnant women in India. Indian J Med Microbiol. 1992;10:53-5.

12. Haider M, Rizvi M, Khan N, Malik A. Serological study of herpes virus infection in female patients with bad obstetric history. Biol Med. 2011;3(2):28490 .

13. Sen MR, Shukla BN, Tuhina B. Prevlance of serum antibodies to TORCH infections in around Varanasi, Northern India. J Clin Diagn Res. 2012;6:1483-5.

14. Vounter LA, Hickok DE, Brown Z, Reid L, Corey L. Recurrent genital herpes simplex virus infection in pregnancy: infant outcome and frequency of asymptomatic recurrences. Am J Obstet Gynecol. 1982;143:75.

Cite this article as: Tiwari S, Arora BS, Sen P, Dewan R. Current status of Immunoglobulin M seroprevalence in women with adverse reproductive outcomes in current pregnancy: experience in a teaching institution. Int $\mathbf{J}$ Reprod Contracept Obstet Gynecol 2016;5:3518-21. 